\title{
Respiratory distress syndrome in preterm infants: possible impact of surfactant application techniques
}

\author{
Pawel Krajewski, Tomasz Pomianek, Krzysztof Truszkowski, Katarzyna Grzyl, \\ Monika Gorska, Miroslaw Wielgos@ \\ Medical University of Warsaw, Poland
}

\begin{abstract}
Objectives: Prematurity is one of the most important issues in perinatology. The most frequent postnatal pathology connected with prematurity is respiratory distress syndrome (RDS) caused by surfactant deficiency due to lung immaturity. RDS is one of the most frequent causes of mortality and morbidity with short- and long-term consequences. The aim of the study was to compare the effectiveness of individual surfactant supply techniques in the treatment of respiratory disorders in premature infants.
\end{abstract}

Material and methods: In the period from the year 2009 to 2013, there were 198 very premature infants that received surfactant included to this retrospective study.

They were divided into three groups based on the surfactant application method:

1. Premature newborns with substitute ventilation, with supply of surfactant through a traditional endotracheal tube - Average gestational age 26.6 weeks; Mean birth weight 911 g; Average Apgar score 4 in $1^{\text {st }}$ minute, 6 in $5^{\text {th }}$ minute.

2. Premature newborns with exogenous surfactant supplementation - InSure method - Average gestational age 28.3 weeks; Average birth weight $1117 \mathrm{~g}$; Mean Apgar score 6 in $1^{\text {st }}$ minute, 7 in $5^{\text {th }}$ minute.

3. Premature newborns with exogenous surfactant supplementation — Less Invasive Surfactant Administration (LISA) method - Mean gestational age 29.9 weeks; Average birth weight $1444 \mathrm{~g}$; Average Apgar score 7 in $1^{\text {st }}$ minute, 8 in $5^{\text {th }}$ minute.

Results: Noninvasive methods of respiratory support and minimally invasive surfactant administration (MISA) significantly reduced the incidence of severe RDS, compared to the traditional method.

Conclusions: Non-invasive methods of respiratory support and MISA like LISA and InSure methods were safe and effective in the treatment of RDS.

Key words: neonatology; continuous positive airway pressure; spontaneous breathing; surfactant; respiratory distress syndrome

Ginekologia Polska 2022; 93, 9: 750-755

\section{INTRODUCTION}

Prematurity is one of the biggest challenges in neonatology. According to the World Health Organization definition, a premature infant is a child born after 22 and before 37 weeks of pregnancy. Newborns born prematurely are at risk of numerous short- and long-term consequences.

Among the short-term consequences respiratory distress syndrome (RDS) is regarded as one of the most crucial. The main causes of RDS are lung immaturity and surfactant deficiency. Untreated RDS could lead to death and is the most common cause of mortality of prematurely born infants.

Until recently, the only standard of management for respiratory failure caused by surfactant deficiency was intubation, endotracheal administration of surfactant and mechanical ventilation, usually continued for many days. All these approaches aim to achieve vital parameters allowing for extubation. This method was associated with damage to the lungs and the development of bronchopulmonary dysplasia. 
Since the beginning of the new millennium, clinicians have started to seek new, less invasive methods for the treatment of respiratory failure in preterm neonates [1, 2]. Implementing noninvasive methods of respiratory support in the early stages after birth has successfully reduced mortality among these patients [3-5] and the incidence of bronchopulmonary dysplasia [6, 7]. These findings were confirmed by the Vermont Oxford Network (VON), Continuous Positive Airway Pressure or Intubation at Birth (COIN) and Surfactant, Positive Pressure, and Pulse Oximetry Randomized Trial (SUPPORT) studies. [8-10].

The use of noninvasive methods of ventilation is insufficient for some patients. These newborns require additional administration of exogenous surfactant because of surfactant deficiency. Research is currently in progress for a method to provide surfactant administration with less invasive methods [11], i.e., inhalation or nebulization [12, 13].

Then, a new method was introduced several years ago: the Intubation, Surfactant Administration and Extubation (INSURE) technique. This method consisted of patient intubation, surfactant administration through thane endotracheal tube and immediate extubation with further use of noninvasive methods of respiratory support, without the need for the continuation of mechanical ventilation [14]. Although great progress has been made, an even less invasive method of administering surfactant was proposed by German researchers: Less Invasive Surfactant Administration (LISA) $[1,15]$. In some Australian centers, this technique is called Minimally Invasive Surfactant Therapy (MIST) [11]. The advantage of this method relies on the administration of surfactant without the need for intubation while continuing noninvasive nasal ventilation. This technique reduces the frequency of failure of noninvasive ventilation $[7,11,16]$, decreases the duration of mechanical ventilation [15-17], the use of oxygen and the incidence of bronchopulmonary dysplasia [7].

\section{Objectives}

The aim of this retrospective study was to compare the effectiveness of each of the three surfactant administration techniques used in the treatment of respiratory failure in premature patients, considering the frequency of complications following each method in the Neonatal Intensive Care Unit (NICU) in a tertiary referral hospital in Lodz, Poland.

\section{MATERIAL AND METHODS}

Study design and patients

The study included patients with a gestational age of 25-32 weeks who were hospitalized from 2009-2013 in the Department of Neonatology, $1^{\text {st }}$ Department of Gynecology and Obstetrics in Lodz, Poland.
The study group consisted of 198 newborns with respiratory failure caused by respiratory distress syndrome. We performed a retrospective analysis of the preterm patient treatment results, depending on the type of treatment that had been used, i.e., the surfactant administration method. Inclusion Criteria:

- Gestational age of 25-32 weeks

- Respiratory Distress Syndrome

- Need of surfactant administration Exclusion Criteria:

- Gestational age different that 25-35 weeks

- Birth defects impacting the respiratory system Three study groups were defined:

1. Preterm babies with mechanical ventilation (MV) who received surfactant administration through an endotracheal tube, followed by MV (Group 1).

2. Preterm babies with exogenous surfactant administration - INSURE method (Group 2).

3. Preterm babies with exogenous surfactant administration - LISA method (Group 3).

Patients in the LISA-treated group were given surfactant via a feeding catheter.

The distribution of patients in each group was as follows: 104 infants in the Intubation+MV group, 60 infants in the INSURE group, and 34 infants in the LISA group.

Poractant alfa (porcine-derived surfactant) was the surfactant used in all our patients.

The distribution of the number and gestational age of patients in each group derives from the fact that in the mentioned period, surfactant administration not followed by mechanical ventilation (Groups 2 and 3) was not routine, the LISA method was very innovative, and formal trials were just beginning.

The following parameters were assessed: patient sex, birth weight, status after birth assessed with the Apgar score (after 1 and 5 minutes) and occurrence of intrauterine fetal growth restriction. From the obstetric point of view, additional parameters were analyzed: type (level) of facility where the patient was delivered, method of birth (via cesarean section or vaginal birth), occurrence of premature rupture of membranes (PROM) and administration of prenatal corticosteroids.

The demographic characteristics of the studied groups are presented in Table 1.

\section{Assessment and endpoints}

We evaluated patient survival rate and the number of complications after treatment of respiratory failure: necessity for surfactant administration, need for oxygen therapy within the first 28 days of life, total length of respiratory support, failure of noninvasive ventilation methods, need 
Table 1. Demographic characteristics of the studied groups

\begin{tabular}{|c|c|c|c|}
\hline & $\begin{array}{l}\text { Intubation + MV } \\
(n=104)\end{array}$ & $\begin{array}{l}\text { INSURE } \\
(n=60)\end{array}$ & $\begin{array}{l}\text { LISA } \\
(n=34)\end{array}$ \\
\hline Week of pregnancy, average (SD) & $26.6(2.5)$ & $28.3(1.8)$ & $29.9(1.9)$ \\
\hline Birth weight, average (SD) & $911(400)$ & $1117(387)$ & $1444(433)$ \\
\hline APGAR 1 min, median (IQR) & $4.0(3.5)$ & $6.0(2.0)$ & $7.0(2.0)$ \\
\hline APGAR 5 min, median (IQR) & $6.0(2.0)$ & $7.0(2.0)$ & $8.0(1.0)$ \\
\hline Boys, n (\%) & $53(51.5)$ & $31(53.4)$ & $19(57.6)$ \\
\hline PPROM, n (\%) & $19(18.3)$ & $15(25.0)$ & $9(26.5)$ \\
\hline C-Section, n (\%) & $76(73.1)$ & $46(76.7)$ & $29(85.3)$ \\
\hline Outborn, n (\%) & $39(37.5)$ & $9(15.0)$ & $6(17.6)$ \\
\hline IUGR, n (\%) & $26(30.2)$ & $25(47.2)$ & $4(14.3)$ \\
\hline
\end{tabular}

SD — standard deviation; IQR - interquartile range; PPROM — preterm premature rupture of membranes; IUGR — intrauterine growth restriction; MV — mechanical ventilation; INSURE — Intubation, Surfactant Administration and Extubation; LISA — Less Invasive Surfactant Admnistration

Table 2. Prenatal steroids, surfactant administration information and respiratory distress syndrome stages

\begin{tabular}{|l|l|l|l|l|}
\hline & $\begin{array}{l}\text { Intubation + MV } \\
\text { (n= 104) }\end{array}$ & $\begin{array}{l}\text { INSURE } \\
\text { (n= 60) }\end{array}$ & $\begin{array}{l}\text { LISA } \\
\text { (n= 34) }\end{array}$ & $\begin{array}{l}\text { p (Insure vs } \\
\text { Intubation + MV) }\end{array}$ \\
\hline Prenatal steroids, $\mathrm{n}(\%)$ & $40(39.2)$ & $27(45.8)$ & $20(58.8)$ & 0.518 \\
Intubation MV)
\end{tabular}

Groups were compared with chi-square or Fisher's exact test; MV — mechanical ventilation; INSURE — Intubation, Surfactant Administration and Extubation; LISA — Less Invasive Surfactant Administration

\begin{tabular}{|c|c|c|c|c|c|}
\hline & $\begin{array}{l}\text { Intubation + MV } \\
(n=104)\end{array}$ & $\begin{array}{l}\text { INSURE } \\
(n=60)\end{array}$ & LISA $(n=34)$ & $\begin{array}{l}p \text { (Insure vs } \\
\text { Intubation + MV) }\end{array}$ & $\begin{array}{l}\text { p (LISA vs Intubation } \\
+ \text { MV) }\end{array}$ \\
\hline BPD, n (\%) & $44(44.0)$ & $29(49.2)$ & $11(32.4)$ & 0.642 & 0.322 \\
\hline Pneumothorax, n (\%) & $16(15.4)$ & $2(3.3)$ & $1(2.9)$ & 0.019 & 0.071 \\
\hline Pulmonary hemorrhage, $\mathrm{n}(\%)$ & $10(9.6)$ & $1(1.7)$ & $2(5.9)$ & 0.057 & 0.730 \\
\hline IVH stage I \& II, n (\%) & $36(35.0)$ & $28(46.7)$ & $9(26.5)$ & 0.190 & 0.482 \\
\hline IVH stage III \& IV, n (\%) & $21(20,4)$ & $7(11,7)$ & $1(2,9)$ & 0.227 & 0.015 \\
\hline PVL, n (\%) & $5(4.9)$ & 7 (11.7) & $0(0.0)$ & 0.202 & 0.331 \\
\hline PDA, n (\%) & $43(41.3)$ & $29(49.2)$ & $15(44.1)$ & 0.424 & 0.933 \\
\hline NEC, $n(\%)$ & $17(16.3)$ & $17(28.3)$ & $6(17.6)$ & 0.104 & $>0.999$ \\
\hline ROP, n (\%) & $26(25.0)$ & $13(21.7)$ & $2(5.9)$ & 0.905 & 0.014 \\
\hline
\end{tabular}

Groups were compared with chi-square or Fisher's exact test; MV — mechanical ventilation; INSURE — Intubation, Surfactant Administration and Extubation; LISA — Less Invasive Surfactant Administration; BPD — bronchopulmonary dysplasia; IVH — intracranial hemorrhage; PVL — periventricular leukomalacia; PDA — persistent ductus arteriosus; NEC — necrotizing enterocolitis; ROP — retinopathy of prematurity

for endotracheal intubation, duration of mechanical ventilation, and occurrence of bronchopulmonary dysplasia, pneumothorax and lung hemorrhage if occurred at any stage of treatment.

The incidence of other conditions connected with prematurity like intracranial hemorrhage (IVH), periventricular leukomalacia (PVL), persistent ductus arteriosus (PDA), retin- opathy of prematurity (ROP), and necrotizing enterocolitis (NEC) was followed.

Two-sided statistical tests with a significance level of 0.05 were used. Depending on whether the data followed a normal distribution, the t-test or Mann-Whitney $U$ test were applied to compare the differences in continuous variables between groups. Discrete variables were compared 
between groups with the chi-square test or Fisher's exact test. The statistical package R version 3.5.1 (www.r-project. org) was used for statistical analysis.

\section{Ethics}

The study was approved by the Bioethics Committee of Medical University of Łódź (number: RNN/6/14/KE, KE/649/14).

Patients' parents and/or legal guardians were counselled before enrolling to the study and they were free to ask questions concerning all procedures. They were asked to sign informed consent forms.

\section{RESULTS}

RDS

The grade of RDS was based on the chest X-ray of the patient.

The difference in the incidence of mild RDS was not statistically significant between the Intubation+MV and INSURE groups $(61.2 \%$ vs $78.3 \%, p=0.14)$ or between the Intubation+MV and LISA groups (61.2\% vs $93.9 \%$, $p=0.001)$. Statistically significant differences were also observed among groups in the incidence of severe RDS. In the group of MV - treated patients, severe RDS was diagnosed more often $(38.8 \%)$ than in the remaining groups - INSURE $(21.7 \%, p=0.041)$ and $\operatorname{LISA}(6.1 \%, \mathrm{p}<0.001)$.

Such a high occurrence of severe RDS might result from the relatively younger gestational age in Group 1 ( 26.6 weeks g.a.), as well as the lack of prenatal steroid therapy in some of the patients. The frequency of prenatal steroid therapy was not significantly different among all groups (MV - 39.2\%; INSURE - 45.8\%; LISA - 58.8\%; MV vs INSURE: $p=0.518$; MV vs LISA: $p=0.073)$. However, the number of doses of antenatal steroids differed among groups.

\section{Prophylactic surfactant}

Prophylactic surfactant was administered up to 15 minutes after birth in $54.8 \%$ of the MV group, in $76 \%$ of the INSURE group and in $42 \%$ of the LISA group. Preventive surfactant administration was significantly more frequent in the INSURE group than in the MV group (76.3\% vs 54.8\%; $\mathrm{p}=0.012$ ).

On the other hand, no statistically significant difference was found in the rate of early surfactant administration among all study groups (MV 29.1\%; INSURE 20.3\%; LISA $26.5 \% ; p=0.298$ ).

\section{Readministration of surfactant}

The need for a second dose (readministration) of surfactant in the INSURE group, in which most of the patients had surfactant administered prophylactically, was significantly lower than that in the MV group (5.3\% vs $17.3 \%$; $p=0.030$ ).

The number of days patients from the studied groups need oxygen therapy was the lowest in the LISA group, but the difference was not statistically significant $(p=0.514)$.

\section{Consequences of preterm birth}

Bronchopulmonary dysplasia is one of the most common negative outcomes of the use of mechanical ventilation and long-term oxygen therapy. The frequency of this complication was lowest in the LISA-treated group (MV: $44.0 \%$; INSURE: $49.2 \%$; LISA: $32.4 \%$; $p=0.32$ ). Pneumothorax occurred significantly less frequently in both the INSURE and LISA groups than in the MV group (MV: 15.4\%; INSURE: $3.3 \%$; LISA: $2.9 \% ; p=0.019$ ).

Regarding the number of cases of pulmonary hemorrhage, no significant differences were identified among the studied groups (MV: 9.6\%; INSURE: 1.7\%; LISA: 5.9\%; $p=0.73$ ).

Analyzing other late consequences of preterm birth, the incidence of intracranial hemorrhage (regardless of grade) was highest in the INSURE group (MV: 35.0\%; INSURE: 46.7\%; LISA: $26.5 \%$; $p=0.48$ ). A significant difference was observed in the rate of severe intra- and periventricular hemorrhage (grade III and IV) in favor of LISA patients compared to MV patients (LISA: $2.9 \%$ vs MV: $20.4 \%, p=0.015$ ).

Periventricular leukomalacia (PVL) occurred more frequently in patients treated with the INSURE method; however, no statistically significant difference was observed compared to the MV group (MV: 4.9\%; INSURE: $11.7 \%$; LISA: $0 \% ; p=0.202$ ). None of the patients from the LISA group presented periventricular leukomalacia.

No significant differences were identified among study groups in the number of cases of patent ductus arteriosus or the need for pharmacological treatment for PDA. It is important to mention that the introduction of pharmacological treatment of PDA for the LISA group was always effective. The need for surgical treatment for PDA was significantly lower in the LISA group than in the MV group (MV: $11.5 \%$; INSURE: $8.3 \%$; LISA: $0 \% ; p=0.038$ ). None of the patients in the LISA group required surgical PDA treatment.

The occurrence of necrotizing enterocolitis (NEC) was the highest in the INSURE group, but the difference was not significant (MV: 16.3\%; INSURE: $28.3 \%$; LISA: 17.6\%; $\mathrm{p}>0.999)$.

Retinopathy of prematurity is another late consequence of preterm birth. A significantly high rate of bronchopulmonary dysplasia (BPD) occurred in the INSURE group. The LISA group had a significantly lower ROP rate than the MV group (MV: 25.0\%; INSURE: 21.7\%; LISA: 5.9\%; $p=0.014$ ). 


\section{DISCUSSION}

Our study showed that both the INSURE and LISA methods of surfactant administration can be considered safe and effective as treatments for RDS. These methods seem to have fewer adverse effects than the classical approach of intubation and the administration surfactant followed by mechanical ventilation.

In our study, [16] both the INSURE and LISA methods significantly reduced the incidence of severe RDS in comparison to the MV method, with LISA being even more effective than INSURE [18]. Although this result might be biased by the lack of antenatal steroid therapy in some of the patients, which was unsatisfactory low in Poland at the time [19], in the MV group as well as the higher percentage of extreme prematurity in the same group of patients, the conclusion agrees with previous studies $[16,18]$.

Consistent with most previous studies, the duration of oxygen dependence was significantly shorter in the LISA group than in the two other studied groups. Similar to most studies, the LISA group had the lowest rate of BPD. $[1,6,7,18,20]$.

As underlined in many previous studies, the benefits of the LISA surfactant administration method might come from the fact that the technique allows for noninvasive respiratory support (such as nCPAP) to be continued during the entire procedure of administering surfactant [21]. This might be the factor preventing the lung injuries that result from mechanical ventilation of any duration [15]. This approach allows the infant to breathe spontaneously during the entire procedure instead of relying on repetitive positive pressure inflations, which might cause faster and more thorough surfactant distribution and absorption [22].

We did not notice any significant differences in the incidence of PDA, although the need for surgical treatment was significantly lower in the LISA group than in the other studied groups.

Regarding the number of cases of ROP and NEC, there was a significant difference between the LISA group and INSURE group. In our study, the INSURE group had a higher rate of both of those complications. This stands in contrast to some of the previous studies in which no significant difference was found [5, 7].

In our study, the INSURE patients seemed to have a significantly lower rate of pulmonary hemorrhage, while patients receiving surfactant with the LISA method had less severe intraventricular and periventricular hemorrhage.

Some of the differences between the results of our study and previous studies [5, 7] might come from the previously stated difference in antenatal steroid administration as well as the number of doses received by the patients' mothers. The preventive type of surfactant administration was much more common in the INSURE group.
The other factors causing the differences between this study and other studies [5, 7] might be the average gestational age, birth weight, and the rate of intrauterine growth restriction (IUGR). Each of these factors could affect the rate of preterm morbidities.

Like other studies [23], we found that noninvasive prophylactic surfactant administration immediately after birth in the delivery room is beneficial for patients and can reduce the need for subsequent doses of surfactant.

\section{CONCLUSIONS}

1. Noninvasive methods of surfactant administration, such as with the LISA and INSURE methods, are safe and effective in the treatment of respiratory distress syndrome, with no increase in the rate of pneumothorax.

2. The prophylactic administration of surfactant in the delivery room using noninvasive or less invasive methods is beneficial for the patient and reduces the need for subsequent doses of surfactant.

3. Noninvasive methods of respiratory support and surfactant administration significantly reduce the incidence of severe RDS.

4. For patients treated with a noninvasive approach, mainly infants from the LISA group, patent ductus arteriosus was more common; however, pharmacological treatment was shown to be effective. None of the patients in this group required surgical treatment of PDA.

5. Patients who were administered surfactant with use of the LISA method had intraventricular and periventricular hemorrhages of lower grades and a lower rate of ROP. Additionally, the frequency of BPD in the LISA group was lower than that in the other groups.

6. In patients treated with the INSURE surfactant administration method, there was a significantly lower incidence of pulmonary hemorrhage, while necrotizing enterocolitis and retinopathy of prematurity occurred more often.

\section{Conflict of interest}

All authors declare no conflict of interest.

\section{REFERENCES}

1. Kribs A, Härtel C, Kattner E, et al. Surfactant without intubation in preterm infants with respiratory distress: first multi-center data. Klin Padiatr. 2010; 222(1): 13-17, doi: 10.1055/s-0029-1241867, indexed in Pubmed: 20084586.

2. Verder H, Robertson B, Greisen $\mathrm{G}$, et al. Surfactant therapy and nasal continuous positive airway pressure for newborns with respiratory distress syndrome. Danish-Swedish Multicenter Study Group. N Engl J Med. 1994; 331(16): 1051-1055, doi: 10.1056/NEJM199410203311603, indexed in Pubmed: 8090164.

3. Krajewski P Chudzik A, Strzałko-Głoskowska B et al Surfactant administration without intubation in preterm infants with respiratory distress syndrome--our experiences. J Matern Fetal Neonatal Med. 2015; 28(10): 1161-1164, doi: 10.3109/14767058.2014.947571, indexed in Pubmed: 25065621 . 
4. Aguar $M$, Cernada $M$, Brugada $M$, et al. Minimally invasive surfactant therapy with a gastric tube is as effective as the intubation, surfactant, and extubation technique in preterm babies. Acta Paediatr. 2014; 103(6): e229-e233, doi: 10.1111/apa.12611, indexed in Pubmed: 24628379.

5. Klebermass-Schrehof K, Wald M, Schwindt J, et al. Less invasive surfactant administration in extremely preterm infants: impact on mortality and morbidity. Neonatology. 2013; 103(4): 252-258, doi: 10.1159/000346521, indexed in Pubmed: 23446061

6. Isayama T, Iwami H, McDonald S, et al. Association of Noninvasive Ventilation Strategies With Mortality and Bronchopulmonary Dysplasia Among Preterm Infants: A Systematic Review and Meta-analysis. JAMA. 2016; 316(6): 611-624, doi: 10.1001/jama.2016.10708, indexed in Pubmed: 27532916.

7. Kanmaz HG, Erdeve O, Canpolat FE, et al. Surfactant administration via thin catheter during spontaneous breathing: randomized controlled trial. Pediatrics. 2013; 131(2): e502-e509, doi: 10.1542/peds.2012-0603, indexed in Pubmed: 23359581.

8. Dunn MS, Kaempf J, de Klerk A, et al. Vermont Oxford Network DRM Study Group. Randomized trial comparing 3 approaches to the initial respiratory management of preterm neonates. Pediatrics. 2011;128(5): e1069-e1076, doi: 10.1542/peds.2010-3848, indexed in Pubmed: 22025591.

9. Morley CJ, Davis PG, Doyle LW, et al. COIN Trial Investigators. Nasal CPAP or intubation at birth for very preterm infants. N Engl J Med. 2008; 358(7): 700-708, doi: 10.1056/NEJMoa072788, indexed in Pubmed: 18272893.

10. Finer NN, Carlo WA, Walsh MC, et al. SUPPORT Study Group of the Eunice Kennedy Shriver NICHD Neonatal Research Network. Early CPAP versus surfactant in extremely preterm infants. N Engl J Med. 2010; 362(21): 1970-1979, doi: 10.1056/NEJMoa0911783, indexed in Pubmed: 20472939.

11. Dargaville PA, Aiyappan A, De Paoli AG, et al. Minimally-invasive surfactant therapy in preterm infants on continuous positive airway pressure. Arch Dis Child Fetal Neonatal Ed. 2013; 98(2): F122-F126, doi: 10.1136/archdischild-2011-301314, indexed in Pubmed: 22684154.

12. Sood BG, Cortez J, Kolli M, et al. Aerosolized surfactant in neonatal respiratory distress syndrome: Phase I study. Early Hum Dev. 2019; 134: 19-25, doi: 10.1016/j.earlhumdev.2019.05.005, indexed in Pubmed: 31121339.

13. Trevisanuto $D$, Marchetto L. Minimally invasive approaches for surfactant administration. Acta Biomed. 2013; 84 Suppl 1: 28-31, indexed in Pubmed: 24049959.

14. More K, Sakhuja P, Shah PS. Minimally invasive surfactant administration in preterm infants: a meta-narrative review. JAMA Pediatr. 2014;
168(10): 901-908, doi: 10.1001/jamapediatrics.2014.1148, indexed in Pubmed: 25089718.


(LISA): chances and limitations. Arch Dis Child Fetal Neonatal Ed. 2019; 104(6): F655-F659, doi: 10.1136/archdischild-2018-316557, indexed in Pubmed: 31296694.

16. Kribs A, Roll C, Göpel W, et al. NINSAPP Trial Investigators. Nonintubated Surfactant Application vs Conventional Therapy in Extremely Preterm Infants: A Randomized Clinical Trial. JAMA Pediatr. 2015; 169(8): 723-730, doi: 10.1001/jamapediatrics.2015.0504, indexed in Pubmed: 26053341.

17. Göpel W, Kribs A, Ziegler A, et al. German Neonatal Network. Avoidance of mechanical ventilation by surfactant treatment of spontaneously breathing preterm infants (AMV): an open-label, randomised, controlled trial. Lancet. 2011;378(9803): 1627-1634, doi: 10.1016/S01406736(11)60986-0, indexed in Pubmed: 21963186.

18. Aldana-Aguirre JC, Pinto $M$, Featherstone RM, et al. Less invasive surfactant administration versus intubation for surfactant delivery in preterm infants with respiratory distress syndrome: a systematic review and meta-analysis. Arch Dis Child Fetal Neonatal Ed. 2017; 102(1): F17-F23, doi: 10.1136/archdischild-2015-310299, indexed in Pubmed: 27852668.

19. Borszewska-Kornacka MK, Gulczyńska E, Kostuch M, et al. Antenatal corticosteroids and respiratory distress syndrome - the first Polish national survey. Ginekol Pol. 2016; 87(7): 498-503, doi: 10.5603/GP.2016.0033, indexed in Pubmed: 27504942

20. Herting $E$, Härtel C, Göpel W. Less invasive surfactant administration (LISA): chances and limitations. Arch Dis Child Fetal Neonatal Ed. 2019; 104(6): F655-F659, doi: 10.1136/archdischild-2018-316557, indexed in Pubmed: 31296694.

21. Herting E. Less invasive surfactant administration (LISA) - ways to deliver surfactant in spontaneously breathing infants. Early Hum Dev. 2013; 89(11): 875-880, doi: 10.1016/j.earlhumdev.2013.08.023, indexed in Pubmed: 24075206.

22. Michna J, Jobe AH, Ikegami M. Positive end-expiratory pressure preserves surfactant function in preterm lambs. Am J Respir Crit Care Med. 1999; 160(2): 634-639, doi: 10.1164/ajrccm.160.2.9902016, indexed in Pubmed: 10430740

23. Stevens TP, Blennow M, Soll RF. Early surfactant administration with brief ventilation vs selective surfactant and continued mechanical ventilation for preterm infants with or at risk for respiratory distress syndrome. Cochrane Database Syst Rev. 2004(3): CD003063, doi: 10.1002/14651858. CD003063.pub2, indexed in Pubmed: 15266470. 